\title{
Diagnóstico e discussão sobre uso da Filtração Lenta para abastecimento público em Santa Catarina, Brasil
}

\section{A diagnosis and discussion about the use of Slow Sand Filtration for public drinking water supply in Santa Catarina, Brazil}

Data de entrada: 08/02/2017

Data de aprovação: $16 / 02 / 2017$

\section{Resumo}

Afiltraçãolentaéuma técnica simples para otratamento deágua euma das mais antigas utilizadas no abastecimento público. Com o tempo, essa tecnologia perdeu espaço para sistemas que demandam, relativamente, menor área útil de ocupação, como a coagulação e a filtração rápida ou direta. Portanto, considera-se que há pouca informação sobre o uso atual dessa técnica de filtração para estudos na área. Em vista disso, esse estudo foi realizado com o intuito de fazer um levantamento e diagnóstico do uso da filtração lenta no estado de Santa Catarina. Estações de tratamento de água com filtros lentos foram identificadas evisitadas em todo o estado; os resultados de questionários aplicados in loco e observações em visitas técnicas são apresentados. Embora simples, observou-se que os problemas encontrados na aplicação da tecnologia estão relacionados à falta de conhecimento específico sobre o assunto. Concluiu-se que a filtração lenta ainda é aplicada no estado e a disseminação de conhecimento sobre a tecnologia é de suma importância para sua preservação, manutenção, melhor aplicação e disseminação em prol de seu uso. Palavras-chave: Abastecimento público. Filtro lento. Operação de ETA.

\section{Abstract}

Slow sand filtration is a simple technique for drinking water treatment and one of the oldest used for drinking water assessment. Over time, it lost its place for systems with coagulation and rapid filtration that demand smaller area prints relatively. Little information about the current application of this technology is found in studies in this field. This study was performed with the intention of making a survey and diagnosis of the use of slow sand filtration in Santa Catarina, Brazil. Water treatment plants with slow filters were identified and visited throughout the state. The results of questionnaires applied in loco and observations on technical visits are presented. The technology is considered simple, nevertheless the problems found in the application of technology are related to the lack of specific knowledge about the subject. Slow sand filtration is still applied in the state and the dissemination of knowledge about the technology is of great importance for its preservation, better application and amplification of its use. Keywords: Public drinking water assessment. Slow sand filter. Drinking water treatment plants operation.

Fernando Hymnô de Souza* - Doutorando no Programa de Pós-graduação em Engenharia Ambiental da Universidade Federal de Santa Catarina (UFSC). Engenheiro Sanitarista e Ambiental. Mestre em Engenharia Ambiental (UFSC). E-mail: fernando.hsaoutlook.com. Bruna Toscano - Graduanda em Engenharia Sanitária e Ambiental na Universidade Federal de Santa Catarina (UFSC).

Carolina Gemelli Carneiro - Mestranda no Programa de Pós-graduação em Engenharia Ambiental da Universidade Federal de Santa Catarina (UFSC). Engenheira Sanitarista e Ambiental (UFSC). Pós-graduada em Gestão Ambiental Municipal pela Universidade do Vale do Itajaí (Univali). Maurício Luiz Sens - Professor Titular no Departamento de Engenharia Sanitária e Ambiental da Universidade Federal de Santa Catarina (UFSC). Engenheiro Sanitarista (UFSC) com Diploma de Estudos Aprofundados e Doutorado em tratamento de água pela École Nationale Superiéure de Chimie de Rennes.

*Endereço para correspondência: Laboratório de Potabilização de Águas, ENS, CTC, UFSC -Campus Reitor João David Ferreira Lima, sn. Bairro Trindade, Florianópolis, Santa Catarina. CEP: 88040-970. 


\section{INTRODUÇÃO}

A filtração lenta é conhecida como a tecnologia mais antiga utilizada para abastecimento público. Existem relatos de sua aplicação na Europa e nos Estados Unidos desde o século XIX (BAKER, 1948). Essa tecnologia consiste na passagem da água a ser tratada por um meio filtrante, poroso, geralmente areia fina, onde o material em suspensão fica retido, principalmente na superfície da areia, por meio de mecanismos de transporte, adesão e pelas atividades biológicas. As velocidades lentas de filtração permitem que a água passe lentamente pela camada de sujeira que se forma pela retenção e decantação de partículas, na parte superior do meio filtrante. Essa camada é biologicamente ativa e tem um importante papel na remoção de patógenos por meio da filtração lenta (HUISMAN; WOOD, 1974).

Com o passar dos anos, essa tecnologia perdeu espaço pelo advento da coagulação e o emprego da filtração rápida, em que se trata cerca de 50 vezes mais água com utilização da mesma área de filtração. A necessidade do uso de fontes de água cada vez maiores e de menor qualidade, para a obtenção de água de melhor qualidade, também contribuiu para que a filtração lenta fosse substituída pelo tratamento por coagulação (DI BERNARDO; BRANDÃO; HELLER, 1999).

Ainda assim, a filtração lenta resistiu ao longo dos anos, tanto no abastecimento público como nas pesquisas. Novos modelos de filtros foram desenvolvidos, alterando a operação ou características dos filtros, como o emprego de retrolavagem para a limpeza (MICHELAN et al., 2011; PIZZOLATTI et al., 2014; SOARES et al., 2010; SOUZA et al., 2016), uso de mantas sintéticas e o uso de carvão ativado granular para o emprego da adsorção (BAUER et al., 1996; CARNEIRO et al., 2016; DI BERNARDO; BRANDÃO; HELLER, 1999; LOGSDON; $\mathrm{KOH}-$ NE; ABEL, 2002). Diversos estudos foram desenvolvidos nos últimos anos a respeito do potencial de remoção de compostos dos quais ainda não se havia conhecimento, os chamados contaminantes emergentes. A exemplo, a filtração lenta apresenta resultados promissores na remoção de tipos diferenciados de agrotóxicos, fármacos, dentre outros (SUMMERS, 2014; ZEARLEY; SUMMERS, 2012).

A existência de estudos com bons resultados nessa área é um motivador à preservação dessa tecnologia. Sistemas de pequeno porte, onde mão de obra qualificada ou recursos são escassos, podem se utilizar da tecnologia com menos dificuldades. A simplicidade do sistema também pode se refletir na segurança, uma vez que facilmente poderia ser bem operado e uma boa operação reflete em uma melhor qualidade da água oferecida, independentemente da tecnologia empregada.

O Estado de Santa Catarina possui 293 municípios, sendo estes diversificados quanto ao oferecimento dos serviços de saneamento. Desse total, 198 municípios são atendidos pela Companhia Catarinense de Águas e Saneamento (Casan), e o restante é administrado por Serviços Autônomos Municipais de Água e Esgoto (SAMAEs) ou Secretarias municipais. No estado, $96,84 \%$ da população urbana é atendida com abastecimento de água (SNIS, 2015). Contudo, informações específicas sobre as tecnologias empregadas para o tratamento utilizado não são simples de obter, como o uso da filtração lenta por exemplo.

Esse artigo tem como objetivo fazer um diagnóstico do uso da tecnologia de filtração lenta para abastecimento público no estado de Santa Catarina, assim como fazer uma discussão crítica a respeito, apontando alternativas para o melhor uso.

\section{METODOLOGIA}

Com o intuito de ter conhecimento sobre as Estações de Tratamento de Água (ETAs) do estado de Santa Catarina que possuem filtro lento em seu sistema de abastecimento, foi feita uma série de pesquisas para se chegar a uma listagem inicial de ETAs que em seguida seriam visitadas. 
Primeiramente, buscou-se na internet o maior número de informações sobre possíveis cidades que continham ETAs com filtração lenta ( $F L)$, enfocando sites que disponibilizavam informações sobre o saneamento do estado (Sistema Nacional de Informações sobre Saneamento - SNIS, Serviços Autônomos Municipais de Água e Esgoto SAMAEs e a Companhia Catarinense de Águas e Saneamento - Casan). Pouco foi encontrado, pois a maioria desses sites não tem disponível a definição de todo o processo de tratamento com detalhes. Dessa maneira, não era possível identificar o tipo de filtro utilizado no local.

Em seguida foi feito contato direto com as agências reguladoras atuantes na época (Agência Reguladora de Serviços de Saneamento Básico do Estado de Santa Catarina - Agesan e Agência Reguladora Intermunicipal de Saneamento - Aris), companhias que prestam serviço de saneamento e a representação no estado da Fundação Nacional de Saúde (Funasa), que auxiliaram na compilação dessas cidades.

A Funasa é o órgão executivo do Ministério da Saúde que atua nas áreas de Engenharia de Saúde Pública e Saúde Ambiental com o propósito de promover a prevenção de doenças por meio de ações de saneamento. Na Funasa levantaram-se dados por meio de busca ativa em processos de financiamento. Contudo, há cidades que constroem filtros lentos com recursos próprios ou outras formas de financiamento que não têm envolvimento com a fundação; logo, foram necessários outros mecanismos de busca.

Por meio do Coordenador de Projetos da Aris, foram levantadas informações sobre mais cidades. A Aris tem como atribuição regular e fiscalizar todas as atividades de saneamento básico; entre elas estão: abastecimento de água, esgoto sanitário, manejo de resíduos sólidos, limpeza urbana e drenagem pluvial. Atualmente, a Aris regula e fiscaliza a concessionária estadual (Casan), empresas privadas e autarquias municipais. Atende 198 municípios de Santa Catarina, de um total de 293 cidades (Aris, 2015).

Os dados passados pela Aris foram obtidos por meio do método de fiscalização utilizado, que é feito in loco. Dessa forma, havia informações sobre o tipo de tratamento utilizado nas ETAs fiscalizadas.

O restante dos municípios era atendido pela Agência Reguladora de Serviços de Saneamento Básico do Estado de Santa Catarina (Agesan), que fiscalizava e orientava a prestação de serviços públicos de saneamento básico e também pôde contribuir na pesquisa feita, fechando assim o nosso levantamento de dados. Após o término desta pesquisa, a Agesan foi extinta, dando lugar à Agência de Regulação de Serviços Públicos de Santa Catarina (Aresc).

Também houve colaboração da Casan. A empresa possui várias filiais, que estão distribuídas entre aproximadamente 198 municípios, e os dados são todos compilados na matriz. A Casan tem como objetivo fornecer água tratada, além de coletar e tratar esgotos sanitários, atua por meio de convênios de concessão firmados com as prefeituras municipais e cobre praticamente todo o estado. Uma relação dos sistemas de tratamento que possuem filtros lentos foi cedida pela empresa.

Dessa forma, após levantamento dos municípios que possuem filtração lenta em Santa Catarina, foi realizado o contato com os responsáveis para a ratificação das informações. Em alguns casos as informações não correspondiam ao que havia sido levantado, ou então era relatado que os sistemas não utilizavam a filtração lenta ou que o sistema de tratamento havia sido modificado e substituído por sistemas convencionais.

A partir disso, os sistemas foram visitados, e as informações, levantadas por meio da aplicação de um questionário respondido pelos responsáveis pelos sistemas e por meio de observação da equipe técnica durante as visitas. 
Além das informações sobre o sistema de tratamento que abastece majoritariamente a população de cada município, também se verificou a existência de outros sistemas isolados que porventura pudessem existir e abastecer significativamente algumas localidades. Para obter esse resultado, foi necessário estar presente durante o diagnóstico, pois tais dados não foram informados na triagem inicial.

Nesse ínterim, para obtenção dessas informações, primeiramente um questionário prévio foi enviado ao responsável (técnico) no local, e durante a visita um questionário completo foi aplicado.

O questionário prévio continha informações gerais do sistema, como capacidade, ligações atendidas, responsáveis e contatos, além de uma solicitação de dados da qualidade de água do sistema. Dessa maneira, os contatos tinham tempo de levantar as informações até o momento da visita.

No momento das visitas, um questionário completo foi aplicado, englobando as mesmas questões do questionário prévio acrescido de perguntas sobre a manutenção do sistema. As perguntas eram feitas de maneira aberta para que os responsáveis pelo sistema pudessem descrever livremente a operação.

Finalizadas as visitas, os dados foram compilados e, em alguns casos, as respostas foram divididas em categorias e interpretadas.

\section{RESULTADOS E DISCUSSÕES}

No estado de Santa Catarina diagnosticou-se que 25 municípios dispõem de ETAs para abastecimento público que utilizam filtros lentos. Portanto, estima-se que essa tecnologia esteja presente em $6 \%$ de todos os municípios do estado, sendo que em 3\%, 11 deles, é o único processo de tratamento utilizado, abastecendo o município de maneira integral (Figura 1). No total, somaram-se 34 estações com dimensões e operação variadas.
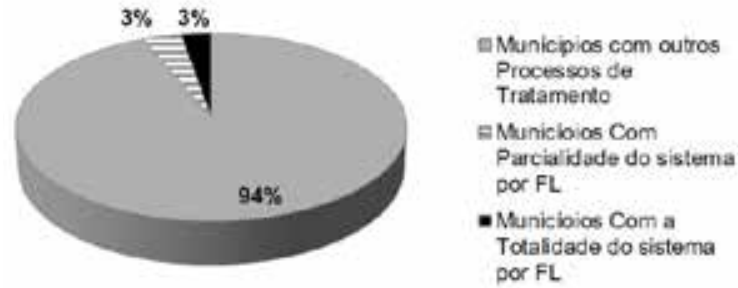

Figura 1 - Municípios com Estações de Tratamento de Água com Filtração Lenta.

Não houve repasse de todas as informações solicitadas por parte dos responsáveis pelos sistemas (Tabela 1). Dessa maneira, os dados reportados são em relação às informações coletadas.

Tabela 1 - Quantidade de locais que forneceram dados a respeito dos parâmetros analisados.

\begin{tabular}{|c|c|c|}
\hline Dados & Número de ETAs analisadas & Porcentagem \\
\hline Fundação & 27 & $79 \%$ \\
\hline Vazão & 28 & $82 \%$ \\
\hline Área & 28 & $82 \%$ \\
\hline $\begin{array}{c}\text { Qualidade da } \\
\text { água tratada }\end{array}$ & 23 & $68 \%$ \\
\hline $\begin{array}{c}\text { Qualidade da } \\
\text { água bruta }\end{array}$ & 14 & $41 \%$ \\
\hline
\end{tabular}

Com relação à quantidade de água que é tratada no estado, a vazão total chega a $271,8 \mathrm{~L} / \mathrm{s}$, com área de filtração de aproximadamente $3406 \mathrm{~m}^{2}$. São cerca de 8,5 bilhões de litros por ano. A população abastecida estimada é de 90 mil pessoas, cerca de 20 mil ligações em todo o estado, segundo dados obtidos nesse estudo.

Esses números são inferiores se comparados à totalidade do estado em estudo. Somente a ETA continental que abastece Florianópolis, a capital do estado, por exemplo, tem capacidade de tratar $2200 \mathrm{~L} / \mathrm{s}$, com previsão de aumento para $3000 \mathrm{~L} / \mathrm{s}$ (ANA, 2015).

Essa discrepância está relacionada à capacidade das ETAs convencionais, que podem tratar água com maior variação de qualidade em menores 
áreas, enquanto para a filtração lenta seria necessária uma água de qualidade superior e maior demanda por área para o tratamento, devido às baixas taxas de filtração.

Além do mais, pôde-se observar que a maioria das ETAs possui área de filtração menor do que $100 \mathrm{~m}^{2}$, sendo a parte mais expressiva com área menor que $50 \mathrm{~m}^{2}$. Isso expressa uma tendência do uso da FL em sistemas de pequeno porte (Figura 2).

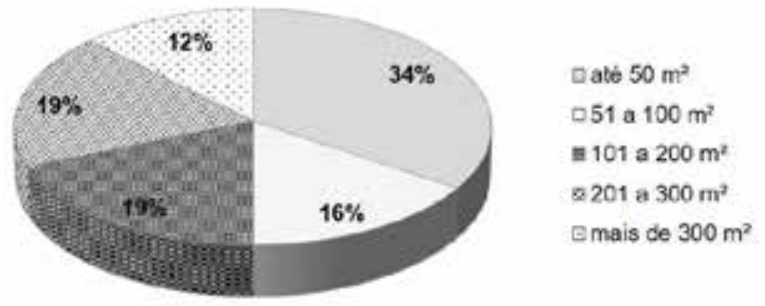

Figura 2 - Área de filtração utilizada.

Sabe-se que ao longo dos anos a FL cedeu espaço a sistemas convencionais (DI BERNARDO; BRANDÃO; HELLER, 1999). Dentre as ETAs visitadas, algumas estão em fase de desativação para se tornarem ETAs convencionais. As motivações relatadas para essa mudança foram, principalmente, a variação da qualidade da água durante períodos de chuva e a deterioração da fonte de água bruta para o sistema.

\subsection{Distribuição Geográfica}

A distribuição dos filtros no estado não é homogênea: a maior parte dos munícipios que se utilizam da tecnologia estão localizados na região Sul, seguida pela Norte, concentrando-se em ambas as regiões o maior número de municípios (Figura 3). As regiões da Serra e da Foz do Itajaí apresentam também uma parte expressiva dos municípios ( $11 \%$ cada uma), seguidas pelas regiões Extremo Oeste e Grande Florianópolis (8\% cada uma). Com menores proporções encontram-se as regiões Oeste e Vale do Itajaí. A região do Meio Oeste não tem municípios com filtração lenta. A distribuição por número de ETAs segue o mesmo padrão de distribuição dos municípios.

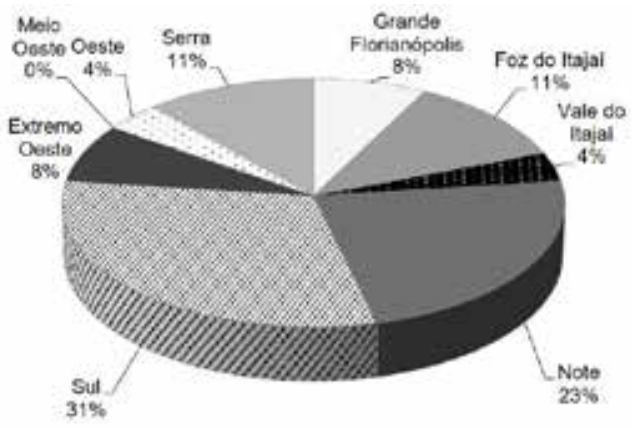

Figura 3 - Distribuição dos municípios com Filtração Lenta em Santa Catarina.

A distribuição diferenciada pode ser por diversas razões, como o relevo, baixa densidade demográfica e recurso para investimentos. As localidades com relevo mais acidentado tendem a ter mais filtros devido à presença de morros e nascentes, o que influencia a qualidade da água, adequada à filtração lenta.

\subsection{Fundação}

A maioria das ETAs foi fundada posterirormente à década de 1990. A mais antiga no estado data de 1966, e a mais nova, de 2004. A ETA mais antiga está localizada na cidade de Pomerode (ETA 1 da SAMAE de Pomerode, Figura 4), na região Norte do estado, e é a segunda maior do estado. Essa ETA atualmente combina coagulação e filtração lenta.

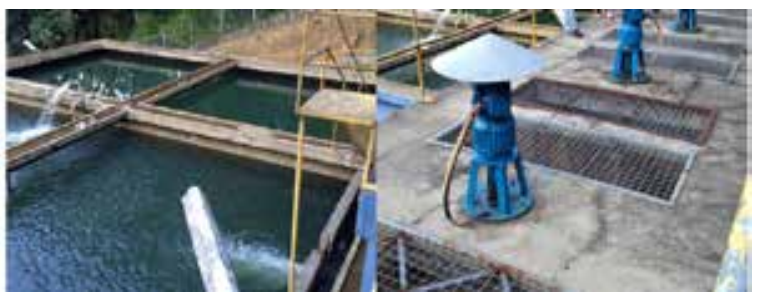

Figura 4 - ETA1 de Pomerode, a mais antiga com filtração lenta no estado. 
Por sua vez, o filtro mais novo encontra-se na cidade de Nova Trento, na região de Foz do Itajaí, em uma estação que foi reformada e aumentada recentemente devido à maior demanda por água tratada.

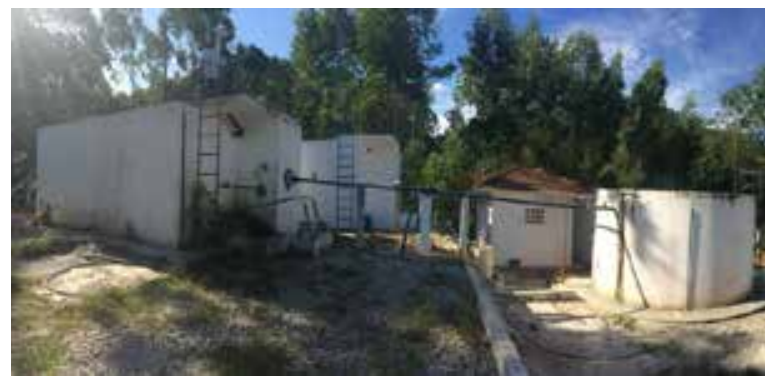

Figura 5 - ETA da Claraíba (ainda em ampliação), Nova Trento.

Embora a maioria dos filtros tenha menos do que 25 anos (Figura 6), a parte mais expressiva foi construída na década de 1990 (11 ETAs), e apenas 11\% foram fundados nos últimos 15 anos (4 ETAs).
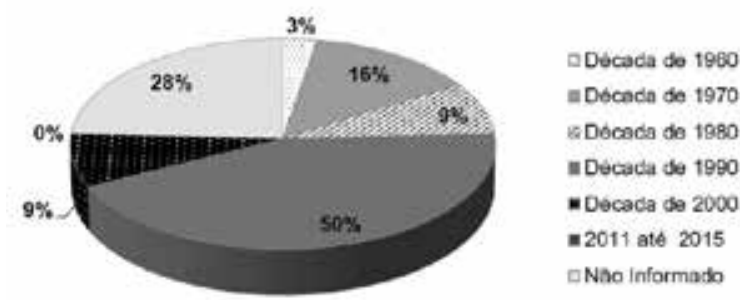

Figura 6 - Fundação das ETAs com Filtração Lenta em Santa Catarina em porcentagem.

\subsection{Profissionais Envolvidos}

A formação dos profissionais com a responsabilidade técnica desses sistemas é diferenciada ( $\mathrm{Fi}-$ gura 7). A maioria dos responsáveis técnicos indicados possui formação em Química. Profissionais de áreas como Engenharia Sanitária e Ambiental, Engenharia Química e Biologia também foram citados como responsáveis.
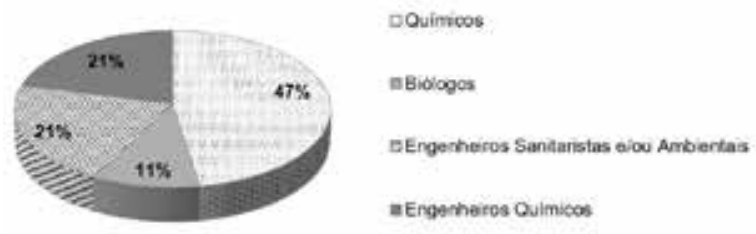

Figura 7 - Formação profissional dos responsáveis técnicos pelas ETAs de Filtração Lenta.

Quanto aos operadores, a maioria não possuía nível técnico ou superior. Isso era esperado, pela simplicidade dos sistemas. Os sistemas têm em média dois operadores, trabalhando de maneira alternada. A maior parte, porém, é mantida por apenas um operador, fazendo um turno médio de $8 \mathrm{~h}$ por dia. Escalas de plantões, in loco ou por uso de celular, são usadas para ocorrências durante a parte da noite e/ou finais de semana, conforme as necessidades de cada local. Ao todo, no estado há cerca de 60 pessoas envolvidas na operação dos filtros lentos, e a minoria tem algum tipo de formação técnica na área.

A maioria dos operadores aprendeu a operar o sistema com seus colegas de trabalho, operadores anteriores ou responsáveis pelos sistemas. Nas visitas, $72 \%$ das pessoas questionadas afirmaram nunca terem participado de algum tipo de formação específica sobre a filtração lenta, sendo a prática diária e o ensinamento de outros colegas a maneira de aprendizado mais recorrente. Embora cursos tenham sido oferecidos aos operadores em alguns locais, a maioria era voltada ao sistema convencional de tratamento.

Uma das vantagens dos sistemas com filtros lentos é a facilidade de operação. Não há necessidade no controle da dosagem de coagulante para o tratamento, assim a formação técnica para tal não é um fator limitante. Dessa maneira, os filtros po- 
dem ser operados com recursos locais, atendendo à demanda com menores gastos. Contudo, problemas encontrados ou reportados durante as visitas poderiam ser simplesmente resolvidos se houvesse informações mais específicas para os operadores dos sistemas, assim como maior acompanhamento e fiscalização das instituições reguladoras.

Também ficou evidente que o fator de decisão para a mudança de tecnologia de filtração lenta para sistemas convencionais (com coagulação) provém de falta de conhecimento a respeito de alternativas, como o uso de pré-filtros ou até mesmo a filtração direta, que emprega coagulação, floculação (se necessário) e filtração, sem sistema de decantação.

Sistemas convencionais são vistos como mais modernos e controláveis, contudo isso não significa que são a única, ou até mesmo a melhor alternativa para o tratamento. Águas com baixa turbidez são mais difíceis de tratar com sistemas convencionais devido à dificuldade de decantação. Acredita-se que o uso dessa tecnologia em locais onde não há mão de obra especializada e que requer apenas contenção de picos de turbidez durante um período do dia não é adequada e pode ser um risco à população abastecida, se mal operado.

A pré-filtração é apontada como uma boa alternativa à contenção de picos de turbidez (DI BERNARDO; BRANDÃO; HELLER, 1999; VERAS; BERNARDO, 2008) e, como discutido posteriormente, existem exemplos de sucesso em sua aplicação no estado.

\subsection{Operação}

Os filtros lentos são caracterizados por sua taxa de filtração, considerada lenta entre 2 e $14 \mathrm{~m}^{3} / \mathrm{m}^{2}$ d. A norma ABNT para a construção de estações de tratamento de água recomenda que a filtração não ultrapasse $6 \mathrm{~m}^{3} / \mathrm{m}^{2} \mathrm{~d}$ quando não é possível fazer um estudo prévio de tratabilidade no local (ABNT, 1992).
Como panorama geral, a maioria dos filtros opera com taxas inferiores à máxima recomendada na norma (Figura 8). Dentre as estações que apresentaram dados de vazão, apenas uma estação opera com taxa acima do recomendado pela literatura, porém, como já citado, o sistema utiliza-se de pré-tratamento com coagulação, garantindo uma água de boa qualidade na saída dos filtros.

A operação com taxas maiores do que o recomendado pela norma (maior que $6 \mathrm{~m}^{3} / \mathrm{m}^{2} \mathrm{~d}$ e inferior à $12 \mathrm{~m}^{3} / \mathrm{m}^{2} \mathrm{~d}$ ) poderia ser explicada pela necessidade de ampliação dos sistemas, que atualmente têm demanda maior do que a capacidade para a qual foram projetados. No entanto, essa não é a realidade desses sistemas, segundo cadastro na ANA (ANA, 2015), sendo a falta de conhecimento no assunto e/ou a boa qualidade da água filtrada as possíveis explicações para o uso dessas taxas.

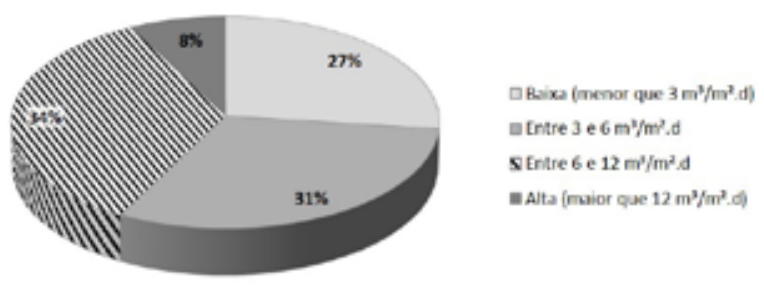

Figura 8 - Taxa de filtração.

Filtração em baixas taxas pode também ser um problema para a utilização da filtração lenta. Por se tratar de um ecossistema, a coluna d'agua acima do leito filtrante necessita de aporte de nutrientes e oxigênio de maneira constante. Devido à alta atividade biológica na superfície do meio filtrante há consumo de oxigênio. Baixas taxas de filtração podem ocasionar falta de oxigênio no sistema, e isso pode acarretar formação de compostos odorantes que não são interessantes na água tratada ou ainda o transpasse de protozoários em busca de melhores condições de oxigênio, prejudicando a filtração (NAKAMOTO, 2014).

Outro limitante ao uso da filtração lenta é a qualidade da água bruta a ser tratada. São recomen- 
dadas águas em que a turbidez não ultrapasse 10 uT. Contudo, dentre as ETAs visitadas, a maior parte não avalia regularmente a água bruta para o tratamento. Dentre aquelas que avaliam, 33\% tratam água com turbidez acima da recomendada, e dentre elas a maioria não atende o exigido na Portaria n 2914 do Ministério da Saúde para a saída dos filtros (BRASIL, 2011), mostrando a necessidade de atender o recomendado para a utilização da tecnologia (Figura 9).

\section{口Sim aNăo $\square$ Naa avalia regularmente}

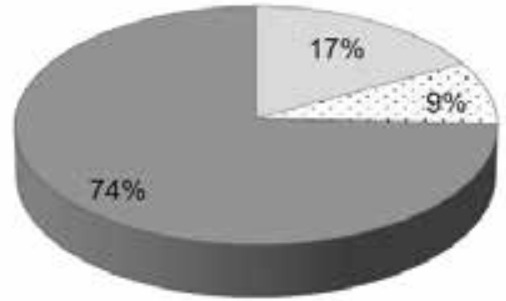

Figura 9 - Adequação da água bruta à filtração lenta.

Um dos problemas mais relatados nas visitas foi que a ocorrência de chuvas altera temporariamente a qualidade da água dos mananciais de captação. Essa alteração temporária tem influência direta na qualidade da água tratada e na operação dos filtros. Além de interferir negativamente na qualidade da água, a água com alta turbidez proveniente dos mananciais no período de chuva causa a diminuição da carreira de filtração. Foram relatadas diminuição para 1 a 3 dias, o que, ao se levar em consideração o tempo e trabalho gastos para a limpeza, é prejudicial à operação.

Diversas são as soluções adotadas nesses casos. Existem sistemas que são desligados no momento das chuvas, o que pode ser feito em estações de fácil acesso e com pessoal disponível para fazê-lo. Algumas estações possuem filtros em espera, sem operação, que são utilizados quando é feita a lim- peza dos filtros em operação. A solução, contudo, não é eficaz em períodos de chuvas recorrentes.

Uma alternativa para esse problema é a utilização de pré-tratamentos que adequem a água bruta para seu tratamento por meio de filtros lentos. Das estações de tratamento do estado, cerca de $24 \%$ utilizam-se constantemente de algum prétratamento. Em duas estações, esse pré-tratamento é a coagulação, floculação e decantação antes da filtração (Figura 10). Em uma delas esse pré-tratamento é utilizado apenas com o aumento da turbidez, onde água decantada de uma ETA convencional que opera paralelamente no local é encaminhada para os filtros lentos também.

Há também filtros que são abastecidos por água de poço e está prevista aeração da água antes dos filtros para eliminação de ferro (Figura 11).

Um tipo de pré-tratamento recomendado para o amortecimento dos picos de turbidez em dias de chuva é a pré-filtração, que pode compor um sistemas de filtração em múltiplas etapas (DI BERNARDO; BRANDÃO; HELLER, 1999) e contribui ainda na remoção de coliformes (CLARKE et al., 2004; NKWONTA; OCHIENG, 2009; VERAS; BERNARDO, 2008). Foram visitados cinco sistemas em todo o estado que possuíam pré-filtros em diferentes concepções (Figura 12). Os tipos utilizados são de pedregulho ou pedregulho e areia grossa, a maior parte deles em fluxo ascendente.

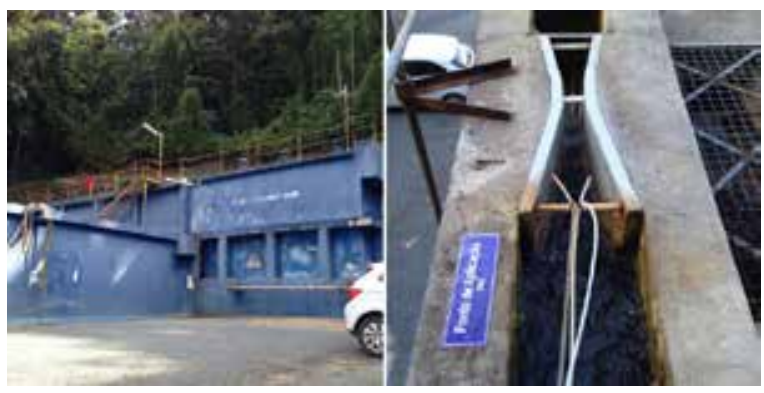

Figura 10 - ETA onde há coagulação, floculação e decantação. 


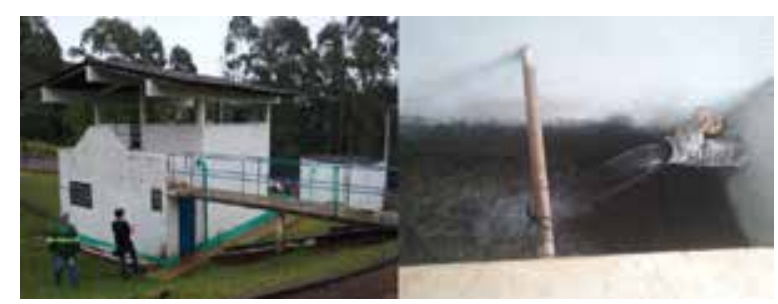

Figura 11 - ETA onde é utilizada aeração.

Figura 12 - Pré-filtros ascendentes utilizados antes de Filtros Lentos.

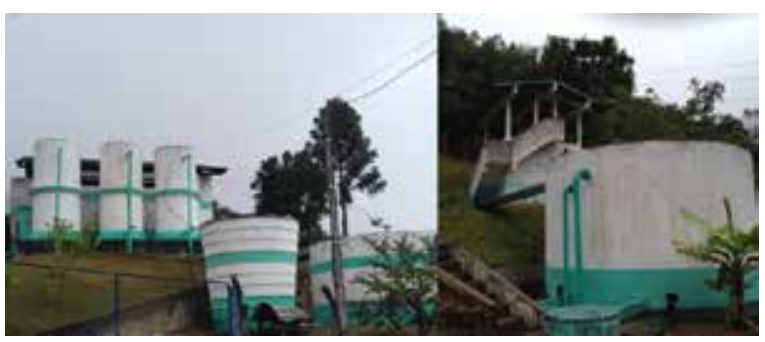

(a) Pré-filtro ascendente em série (esq.) e pré-filtro ascendente em camadas (dir.).

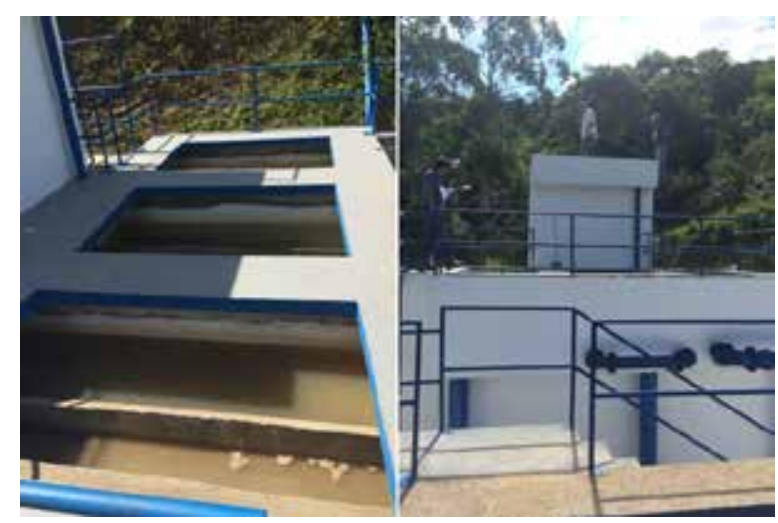

(b) Pré-filtro ascendente de pedregulho e areia grossa.

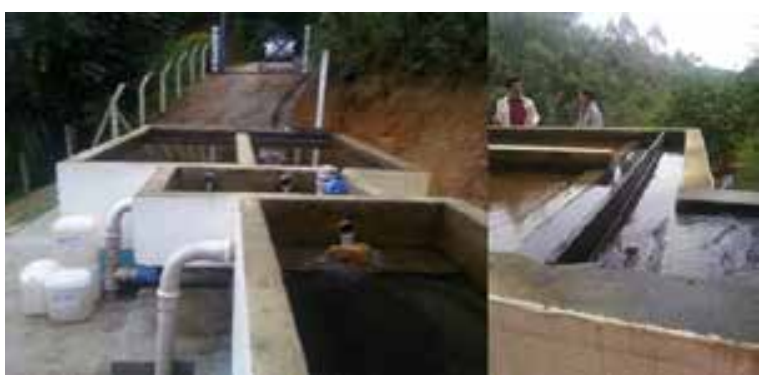

(c) Pré-filtro descendente em camadas e pré-filtro ascendente de antracito.

\subsection{Qualidade da Água Filtrada}

A filtração lenta é indicada para tratar águas de qualidade superior às utilizadas no tratamento convencional, com turbidez abaixo de 10 uT (HUISMAN; WOOD, 1974), quantidade de matéria orgânica abaixo de $4 \mathrm{mg}$ de DBO5/L e coliformes totais entre 100 e 5000 NMP/100 mL (ABNT, 1992).

Ou seja, as estações que operam com filtros lentos devem ser administradas consoante ao que estabelece a Política Nacional dos Recursos Hídricos, Lei 9.433 (BRASIL, 1997) e ao Novo Código Florestal, Lei 12.651 (BRASIL, 2012), no intuito de proteger mananciais e assegurar a qualidade de água bruta, a fim de evitar gastos futuros e sobrecarga no sistema de tratamento.

A tecnologia garante a remoção de materiais suspensos e tem boa eficiência em remoção de patógenos por meio de mecanismos biológicos. $\mathrm{O}$ exigido pela norma de potabilidade é que os filtros lentos sejam monitorados ao menos uma vez ao dia e $95 \%$ das amostras não podem apresentar valores maiores do que 1 uT e devem estar em sua totalidade abaixo de 2 uT.

Os dados apresentados por essa pesquisa foram variados de acordo com a disponibilidade de fornecimento de cada local. $O$ que se nota é que nem todos os locais fazem acompanhamento da água filtrada, e sim após a cloração. Nem todos afirmaram fazer o acompanhamento da água bruta.

Dentre os municípios que apresentaram os dados, $100 \%$ apresentaram água adequada na saída do tratamento. Dentre esses dados, $57 \%$ estavam de acordo com a norma para a saída dos filtros.

A turbidez é o único parâmetro a ser controlado a respeito de qualidade da água filtrada, e valores muito altos representam a ineficiência do processo. A turbidez maior do que o recomendado, mesmo após a desinfecção, pode representar um problema do sistema de tratamento em si. Considera-se inadequado, mesmo que de acordo com 
a Portaria (BRASIL, 2011), que $43 \%$ das ETAs ainda apresentem água com turbidez acima de 2 uT logo após o tratamento, onde ainda não houve influência alguma da rede de distribuição.

Conformar-se aos padrões de turbidez estabelecidos é de grande importância, uma vez que uma filtração eficiente é primordial para o processo de tratamento de maneira geral. A filtração lenta, por exemplo, tem alta capacidade de remoção de cistos de protozoários como Cryptosporidium spp. e Giárdia spp. e que precisam de altas dosagens de cloro ou tempo de detenção elevados para a sua remoção (BELLAMY et al., 1985).

\subsection{Limpeza Dos Filtros}

A limpeza de filtros lentos é considerada a parte mais trabalhosa de sua operação. Usualmente nesse processo o filtro é drenado até que a superfície da areia esteja exposta. Dessa maneira é feita a raspagem do schmutzdecke e os primeiros centímetros de areia que são lavados externamente ao filtro, e a areia é recolocada no filtro.

Alternativas a esse processo foram identificadas nas visitas feitas às ETAs, porém dentre os procedimentos de limpeza adotados a maioria é a raspagem ou alguma variação desta (Figura 13).

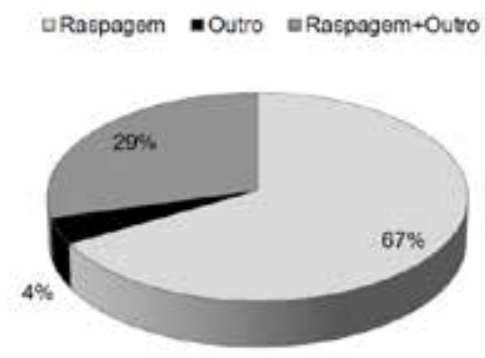

Figura 13 - Método de limpeza dos filtros lentos.

Dentre as ETAs, nenhuma possuía depósito de areia. A maioria repõe a areia logo após a limpeza, e as que não o fazem jogam a areia fora ou a uti- lizam para outros fins. O fato de jogar a areia fora gera um custo na manutenção dos filtros diferenciado daquele em que a areia é lavada.

A maioria dos sistemas visitados que têm essa prática utiliza areia específica para filtros de ETAs, que tem custo elevado. Os custos relatados variaram de $R \$ 600,00$ (seiscentos reais) a $R \$ 750,00$ (setecentos e cinquenta reais) por metro cúbico. Onde se utilizam recursos locais, a areia é a mesma da construção civil, que é lavada e colocada nos filtros. $O$ custo relatado é de aproximadamente $\mathrm{R} \$ 60,00$ (sessenta reais) por metro cúbico.

Para lavar a areia de maneira prática existem lavadores de areia. Basicamente são tanques onde é aplicado um fluxo ascensional de água. Dos sistemas visitados, $24 \%$ possuíam um lavador de areia, alguns deles na área interna do filtro, minimizando a mão de obra para retirar a areia de dentro do filtro (Figura 14).

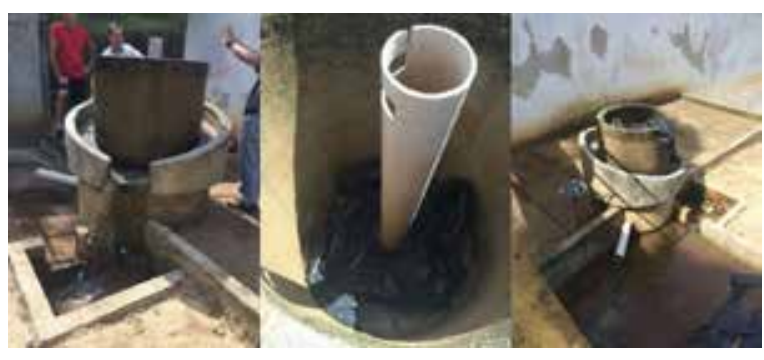

Figura 14 - Lavador de areia.

A reposição da areia no filtro foi um assunto que gerou discussão em todas as visitas em que o assunto era abordado (no caso daqueles locais que a jogavam fora). Muitos locais não sabiam que a areia poderia ser reposta ou não o faziam, pois não tinham estrutura para fazer a lavação. Outros locais afirmaram o contrário, que é mais simples repor a areia do que fazer a lavação, por ser um processo trabalhoso e demorado.

Como já citado, nenhum sistema visitado possuía algum tipo de depósito de areia. A existência desse depósito seria uma alternativa aos sistemas em 
que o tempo de limpeza é significativo na produção de água tratada. Em sistemas onde existe o depósito, os filtros podem voltar a operar antes de a areia ser reposta, desde que haja profundidade suficiente de meio filtrante $(60 \mathrm{~cm}$, como recomendado pela NBR ABNT 12216, 1992). Essa areia pode ser estocada e recolocada apenas quando a profundidade mínima for atingida.

\subsection{Características de Projeto}

\subsubsection{Cobertura e incidência solar}

Não há especificações em norma quanto à cobertura de filtros. A existência de incidência de luz solar é um fator influente na operação do filtro, uma vez que ele é considerado um ecossistema e a presença e ausência de luz tem influência nisso.

A maioria dos filtros visitados não era coberta, e dentre os cobertos variou-se o tipo de cobertura, como telhados que cobriam parcialmente os filtros, locais inteiramente fechados ou coberturas que fechavam totalmente os filtros. Dentre os abertos, nem todos estavam em locais onde havia incidência solar.

Foram relatados problemas relacionados à incidência solar, o que levou inclusive à cobertura de alguns filtros visitados. $O$ problema relatado era o da proliferação de algas ou microalgas, que dificultavam a operação, causando problemas de redução da carreira de filtração.

Na literatura são relatadas diferentes experiências relacionadas à incidência de luz solar em filtros lentos, em sua maior parte ao desenvolvimento de perda de carga nos filtros devido à presença de algas. $O$ consenso é de que altas densidades de algas contribuem com o desenvolvimento de perda de carga; contudo, se a presença de algas é controlada pode-se ter um desempenho ainda melhor do sistema, até prolongando a carreira de filtração (HUISMAN; WOOD, 1974; IWASE et al.,
2006; JABUR, 2006; KELKAR; TAJNE; DHAGE, 2009; NAKAMOTO, 2014).

A presença de algas está relacionada com a presença de oxigênio dissolvido no sistema, o que favorece a proliferação de organismos relacionados ao seu consumo, intensificando atividades biológicas. Segundo NAKAMOTO (2014), as algas têm um papel imprescindível na disponibilidade de oxigênio no sistema, e a falta desse pode acarretar no transpasse de microrganismos para o efluente do filtro. 0 mesmo autor afirma que deve haver controle da densidade de algas no sistema, uma vez que também estão relacionados ao consumo em momentos sem incidência de luz solar.

Na prática, tal controle seria um cuidado a mais com o sistema. $\mathrm{O}$ que se observa na realidade catarinense é que os sistemas são operados como um tratamento puramente físico, ou majoritariamente físico, e o controle biológico do sistema é algo além dessa realidade.

Um controle biológico do sistema pode ser algo que está além da realidade de operação de filtros no estado, e até mesmo no Brasil, uma vez que a norma existente sugere também esse comportamento, sendo a turbidez o único parâmetro a ser observado na água filtrada por esses sistemas. Nenhum outro parâmetro está atrelado à eficiência desse sistema em si.

Tendo em vista a realidade dos sistemas visitados e o tipo de aplicação que é dada aos filtros lentos, isso é algo coerente, uma vez que se desejam sistemas de simples operação, sem a necessidade de mão de obra especializada.

No entanto, o desenvolvimento de algas ainda está relacionado à qualidade da água bruta e nem sempre a incidência de luz solar é determinante para sua proliferação, o que explica o fato de diversos filtros existentes não apresentarem problemas relacionados a isso. 


\subsubsection{Meio filtrante}

De acordo com a NBR ABNT 12 216/92, o meio filtrante em filtros lentos deve ter diâmetro efetivo entre $0,25 \mathrm{~mm}$ e $0,35 \mathrm{~mm}$ e coeficiente de uniformidade de até 3 (ABNT, 1992). Essa areia é mais fina do que as utilizadas em filtros rápidos, por não se utilizarem processos de coagulação antes da filtração. $O$ coeficiente de uniformidade é maior, pois aceita-se uma variação maior do tamanho dos grãos, uma vez que não é feita a retrolavagem e a fim de facilitar a obtenção de areia a menor custo e com maior facilidade.

Dentre as ETAs visitadas, a maioria não retornava a areia lavada aos filtros, sendo necessária a compra do material e sua reposição periodicamente. Foram relatados casos de até duas reposições ao ano com custos que variam de $\mathrm{R} \$ 60,00$ a $\mathrm{R} \$ 750,00 / \mathrm{m}^{3}$. Os valores inferiores são relacionados ao uso de areia de aluvião, comprada na localidade, e os valores elevados, a areias especiais para filtros.

O uso da areia mais barata é uma vantagem relacionada à filtração lenta. Contudo, na prática, gastos elevados foram reportados com a reposição do meio filtrante. Somam-se como motivos a esses gastos o descarte do meio filtrante, sem reaproveitamento, e o tipo de areia utilizada. Embora a areia especial para filtro esteja sendo amplamente utilizada, não fica garantido que o especificado por norma seja atendido, uma vez que poucos souberam informar as características do meio filtrante utilizado e, dentre os informados, a maioria possuía granulometria maior que a estabelecida.

Esse problema, contudo, reflete pouco na qualidade da água reportada, uma vez que a maioria dos sistemas se apresentou eficiente. Nesse caso, o impacto econômico na operação do sistema é o maior problema, uma vez que o indicado é que a areia dos filtros seja lavada e reposta, não havendo necessidade de reposição imediata. Ou seja, com a existência de um depósito, as ETAs poderiam economizar na compra de areia e no tempo de filtro inoperante recolocando o filtro em operação, lavando a areia e estocando, até que a espessura mínima $(60 \mathrm{~cm})$ seja atingida. Nesse momento toda a areia poderia ser reposta de uma só vez.

\subsubsection{Saída de água filtrada}

De acordo com a norma, a saída de água dos filtros deve ser acima do nível do meio filtrante para garantir que não haja pressão negativa no filtro (ABNT, 1992). Pressão negativa é um problema na operação de filtros por gravidade, uma vez que altera as taxas de filtração e pode acarretar na formação de bolhas no meio filtrante, também interferindo no processo de filtração.

Uma alternativa para o controle de pressões negativas é o uso de registro para a regulagem da pressão; contudo, recomenda-se o uso de piezômetros para uma operação e monitoramento adequados.

Foi observado, nas ETAs visitadas, saídas em câmaras com vertedores, que garantiam a saída da água em um nível acima do meio filtrante. Também havia saídas em tubulações com registros de gaveta, onde eram controladas pressão e vazão da água. Contudo, apenas um sistema possuía piezômetros para o acompanhamento das pressões nos filtros e na saída da água filtrada.

Alguns sistemas não possuíam as saídas acima do leito filtrante, sendo o escoamento da água controlado na entrada dos reservatórios, sem qualquer controle para evitar-se pressão negativa. Foram relatados problemas com a carreira de filtração, bolhas de ar e qualidade da água.

\section{CONCLUSÕES}

Com o trabalho realizado, pôde-se concluir que:

- O uso da filtração lenta é uma realidade no estado de Santa Catarina, embora seja muito inferior ao de sistemas convencionais de tratamento; 
- Percebe-se um fomento na substituição dos sistemas com filtração lenta para sistemas convencionais de tratamento, mesmo que desnecessário, no intuito de experimentar a tecnologia e a fim de remediar problemas corriqueiros e de fácil solução, como proteção do manancial;

- A realidade climática de grandes precipitações concentradas em um período do dia não é relatada na literatura internacional, e é o maior problema relatado a respeito da operação dos sistemas. Dessa maneira, a concepção de sistemas de múltiplas etapas, empregando pré-filtros, é considerada mais adequada na região;

- Verificou-se que uma das causas de problemas para esse tipo de tratamento é a falta de preservação em torno de fontes e mananciais onde acontece a captação de água. Portanto, as adequações necessárias deveriam estar relacionadas ao cumprimento das leis vigentes de proteção, evitando assim gastos excessivos com novas tecnologias paliativas, como as que foram observadas;

- A falta de conhecimento específico a respeito da filtração lenta e variantes, sua simplicidade, limitações a respeito da qualidade da água bruta a ser tratada e processo de limpeza faz com que a tecnologia perca espaço para outras consideradas mais modernas;

- Problemas relatados poderiam ser facilmente resolvidos caso houvesse o mínimo de conhecimento técnico específico a respeito da tecnologia e com mínimo de investimento;

- Há necessidade da divulgação de tecnologias simples de tratamento de água para abastecimento público com real possibilidade de aplicação, e não apenas como uma alternativa de simplicidade e baixo custo. Assim como em diversos meios profissionais relacionados ao tratamento de água para abastecimento, uma vez que os envolvidos possuem formação diversificada.

\section{AGRADECIMENTOS}

Os autores desse trabalho agradecem a todos os profissionais da Funasa, da Aris e da Agesan envolvidos no levantamento das ETAs de filtração lenta. Ainda, aos responsáveis técnicos e operadores dos locais visitados pelo fornecimento dos dados e acompanhamento nas visitas técnicas. E, por fim, ao engenheiro F. M. Moreira pelo apoio nas visitas técnicas na região Oeste de Santa Catarina. Os pesquisadores F. H. de Souza e C. G. Carneiro receberam auxílio (bolsa de doutorado e mestrado, respectivamente) do Conselho Nacional de Desenvolvimento Científico e Tecnológico (CNPq). O projeto como um todo foi financiado pela Funasa, como parte do Programa de Pesquisa em Saúde e Saneamento, edital n 01/2011, sob convênio nº 0394/2011 entre Funasa, UFSC e Fundação de Amparo à Pesquisa e Extensão Universitária (Fapeu).

\section{REFERÊNCIAS}

ABNT. ABNT NBR 12216: Projeto de estação de tratamento de água para abastecimento público. Rio de Janeiro: ABNT, 1992.

ANA. ATLAS - Abastecimento Urbano de Água. Disponível em: <http://atlas.ana.gov.br/Atlas/forms/Home.aspx>. Acesso em: 26 ago. 2015.

ARIS. A Aris / ARIS - Agência Reguladora Intermunicipal de Saneamento. Disponível em: <http://www.aris.sc.gov.br/institucional>. Acesso em: 26 ago. 2015.

BAKER, M. N. The quest for pure water; the history of water purification from the earliest records to the twentieth century. New YorkAmerican Water Works Assn., , 1948.

BAUER, M. et al. The GAC/slow sand filter sandwich - From concept to commissioning. Water Supply, v. 14, n. 2, 1996.

BELLAMY, W. D. et al. Removing Giardia Cysts with slow sand filtration. Journal of American Water Works Association, v. 77, n. 2, p. 52-60, 1985.

BRASIL. Congresso Nacional. Lei Federal no 9.433, de 8 de Janeiro de 1997. Institui a Política Nacional de Recursos Hídricos e dá outras providências. Diário Oficial da União. Brasília-DF, Brasil, 1997.

BRASIL. Ministério da Saúde. Portaria No 2914. Dispõe sobre os procedimentos de controle e de vigilância da qualidade da água para consumo humano e seu padrão de potabilidade. Diário Oficial da União. Brasília-DF, Brasil, 2011. 
BRASIL. Congresso Nacional. Lei Federal no 12.651, de 25 de Maio de 2012. Dispõe sobre a proteção da vegetação nativa e dá outras providências. Diário Oficial da União. Brasília-DF, Brasil, 2012.

CARNEIRO, C. G. et al. Desenvolvimento de um sistema alternativo para o tratamento de água oriunda de nascente em propriedades rurais. IN $27^{\circ}$. Encontro Técnico AESABESP. Anais...São Paulo: 2016

CLARKE, B. A. et al. Multi-stage filtration for developing world surface water treatment. Proceedings of the ICE - Water Management, v. 157, n. Setembro, p. 143-149, 2004.

DI BERNARDO, L.; BRANDÃO, C. C. S.; HELLER, L. Filtração em múltiplas etapas. PROSAB 1- ed. Rio de Janeiro: ABES - Associação Brasileira de Engenharia Sanitária e Ambiental, 1999.

HUISMAN, L.; WOOD, W. E. Slow sand filtration. Geneva, Belgium: World Health Organization, 1974.

IWASE, N. et al. Role of algal growth and photosynthesis in slow sand filters as an advanced wastewater treatment. In: GIMBEL, R.; GRAHAM, N. J. D.; COLLINS, M. R. (Eds.). Recent Progress in Slow Sand and Alternative Biofiltration Processes. London: IWA Publishing, 2006. p. 60-67.

JABUR, H. S. The effect of water temperature on the slow sand filter process. In: GIMBEL, R.; GRAHAM, N. J. D.; COLLINS, M. R. (Eds.). Recent Progress in Slow Sand and Alternative Biofiltration Processes. London: IWA Publishing, 2006. p. 74-77.

KELKAR, P.; TAJNE, D.; DHAGE, S. Effect of shading on performance of slow sand filters. Journal: American Water Works Association n. Dezembro, p. 69-76, 2009.

LOGSDON, G.; KOHNE, R.; ABEL, S. Slow sand filtration for smal water systems. Journal of Environmental Engineering and Science, v. 348, p. 339-348, 2002.

MICHELAN, D. C. DE G. S. et al. Desempenho do sistema filtração em margem seguida de filtração lenta retrolavável em Ituporanga Santa Catarina. Revista DAE, v. 59, n. 187, p. 28-36, 2011.
NAKAMOTO, N. Food chain is the key in ecological purification system: new concept and new name of slow sand filter. In: NAKAMOTO, N. et al. (Eds.). Progress in Slow Sand and Alternative Biofiltration Processes: Further Developments and Applications. 1st. ed. London: IWA Publishing, 2014. p. 540.

NKWONTA, O.; OCHIENG, G. Roughing filter for water pre-treatment technology in developing countries: a review. International Journal of Physical Sciences, v. 4, n. 9, p. 455-463, 2009.

PIZZOLATTI, B. S. et al. Comparison of backwashing with conventional cleaning methods in slow sand filters for small-scale communities. Desalination and Water Treatment, v. 54, n. January 2014, p. 1-7, 6 jan. 2014.

SNIS. Sistema Nacional de Informações sobre Saneamento Tabela Resumo de Informações e Indicadores Por Estado. Disponível em: <http://www.snis.gov.br/diagnostico-agua-e-esgotos/diagnostico-ae-2015>. Acesso em: 25 jan. 2017.

SOARES, M. B. D. et al. Backwashed Slow Sand Filtration for Water Supply during Droughts Periods in Animal Production. 21st Century Watershed Technology: Improving Water Quality and Environment, v. 2010, n. 701, p. 21-24, 2010.

SOUZA, F. H. DE et al. Study of slow sand filtration with backwash and the influence of the filter media on the filter recovery and cleaning. Environmental Technology, v. 37, n. 14, p. 1802-1810, 17 jul. 2016.

SUMMERS, R. A Review of Biologically-Based Drinking Water Treatment Processes for Organic Micropollutant Removal. In: NAKAMOTO, N. et al. (Eds.). Progress in Slow Sand and Alternative Processes: Further Developments and Applications. 1st. ed. [s.l.] IWA Publishing, 2014.

VERAS, L.; BERNARDO, L. DI. Water treatment by multistage filtration systems-MSF. Engenharia Sanitaria e Ambiental, v. 13, n. 1, p. 109-116, 2008.

ZEARLEY, T. L.; SUMMERS, R. S. Removal of trace organic micropollutants by drinking water biological filters. Environmental science \& technology, v. 46, n. 17, p. 9412-9, 4 set. 2012. 